\section{Balancing Landscape Preferences and Water Conservation in a Desert Community}

\author{
Jane E. Spinti, ${ }^{1}$ \\ Rolston St. Hilaire, ${ }^{2}$ and \\ Dawn VanLeeuwen ${ }^{3}$
}

Additional INDEX WORDS. arid, desert plants, southwestern United States, survey instrument

SummARY. We surveyed homeown-
ers with residential landscapes in Las
Cruces, N.M., to determine design
features participants valued in their
landscapes, their attitudes toward
the landscape use of desert plants
and opinions on factors that would
encourage respondents to reduce land-
scape water use. We also determined
whether the willingness to use desert
plants in their landscapes related to
the length of residency in the south-
western United States. At least $98 \%$
of respondents landscaped to enhance
the appearance of their home and in-
crease their property value. About half
(50.6\%) of the participants strongly
agreed or agreed that the main reason
to landscape was to display their land-
scape preferences. Many participants
indicated they would use desert plants
to landscape their front yard (80.3\%)
and back yard (56.3\%), but relatively
lower percentages of participants
actually had desert landscapes in their
front yard and back yard. Regardless
of their property value, respondents
were more likely to use desert plants
in their backyard the shorter their
stay in the desert. Data revealed that
participants rank water shortages
as the factor that would most likely

Contribution of the New Mexico Agricultural Experiment Station, New Mexico State University, Las Cruces and the Rio Grande Basin Initiative Project. We thank Camile Cisneroz, Luke Gilpen, Brenda Seevers, Esther Solis, and John White for their assistance on this project.

${ }^{1}$ Former graduate student, Department of Agronomy and Horticulture, New Mexico State University, Box 30003, Las Cruces, NM 88003.

${ }^{2}$ Assistant professor, Horticulture, New Mexico State University, Box 30003, Las Cruces, NM 88003. Corresponding author; rsthilai@nmsu.edu.

${ }^{3}$ Agricultural Biometric Service, New Mexico State University, Box 30003, Las Cruces, NM 88003. cause them to reduce the amount of water they applied to their landscapes. We conclude that homeowners report willingness to use desert plants but desert-type landscapes are not a widespread feature of managed residential landscapes. Furthermore, water shortages and the length of time respondents spent in a desert environment would most likely influence water use in their landscapes.

I n the United States, residential water use averages $371.0 \mathrm{~L} \cdot \mathrm{d}^{-1}(98$ $\mathrm{gal} / \mathrm{d}$ ) per person and is highest in desert states (Emrath, 2000). Average residential water use ranges from a low of $208.2 \mathrm{~L} \cdot \mathrm{d}^{-1}(55 \mathrm{gal} / \mathrm{d})$ per person in Wisconsin to a high of $783.6 \mathrm{~L} \cdot \mathrm{d}^{-1}(207$ $\mathrm{gal} / \mathrm{d}$ ) in Nevada (Emrath, 2000). Water consumption is probably highest in desert states because of climate-related differences in outdoor water use, such as landscape irrigation (Emrath, 2000). In fact, in urban environments of arid regions of the U.S., landscape irrigation consumes about $40 \%$ of all residential water use (Ferguson, 1987).

Because of this high water usage, dwindling water resources, escalating water prices, and increasing urbanization, municipalities in arid regions of the southwestern U.S. (Arizona, California, Nevada, New Mexico, and Utah) have implemented water conservation programs. Effective water conservation strategies are likely to arrest consumptive depletion of underground aquifers (Earp et al., 2000 ), preserve water quality (Brown et al., 2000) and stabilize future water supplies of the arid southwestern U.S. (Southwest). But, water conservation strategies should also include longterm public awareness campaigns, meaningful education programs and effective ordinances to be successful. Therefore, public opinion surveys must be commissioned to generate information that is useful to water conservation programs.

Public perception surveys can determine consumer landscape preferences (Lohr and Bummer, 1992; Thayer, 1982), attitudes to water conserving landscapes (Kuo et al., 1998; Lockett et al., 2002; Zube et al., 1986) and plant selection factors important to landscape designers and landscape architects (Barton et al., 1998). For example, public opinion surveys have determined that homeowners prefer 
traditional urban landscapes that include irrigated, nonnative shrubs, trees and turfgrass (Cotter and Croft, 1974; Kennedy and Zube, 1991; Zube et al., 1986). However, a public opinion survey of Lohr and Bummer (1992) demonstrated that traditional landscapes could look as pleasing and attractive as water-conserving landscapes and a brief videotape could effectively alter attitudes of people toward water-conserving landscapes.

The use of drought-tolerant, native plants is an important component of water-conserving landscapes (Paine et al., 1992). In addition, desert landscapes may be preferred over other landscapes (Herzog and Barnes, 1999; Lyons, 1983) because residents perceive that they conserve water. Desert landscapes refer to designed or natural landscapes with plants (desert plants) that are adapted to arid areas. Desert plants are able to survive in arid areas with little supplemental irrigation. With the perception that the simple use of desert plants will save water, homeowners may select those plants as one way to conserve water in a desert environment.

How homeowners balance landscape choices with water conservation issues in the desert environment of the Southwest is unknown. The objectives of this study were to determine 1) design features valued in managed landscapes, 2) whether desert plants are valued in landscapes, 3 ) the influence of time spent in the Southwest on the acceptance of desert landscapes, and 4) the factors that could reduce the amount of water applied to residential landscapes.

\section{Materials and methods}

SURVEY INSTRUMENT DEVELOPMENT AND PRETESTING. We developed a descriptive survey instrument to determine the design features homeowners valued in their residential landscapes, their attitudes toward the use of desert plants in managed landscapes, and opinions on factors that could help reduce the amount of water homeowners apply to residential landscapes. Also, we used survey data to explore the relationship between residency in the Southwest and landscape preferences of participants. Information gathered on each participant included the number of years spent at their residential property and whether they were native to the Southwest. Also, participants gave the number of years they lived in any arid-semiarid region, rural area or the Southwest. We also asked participants to indicate the amount of time they had lived outside of those areas. In addition, participants were asked about their knowledge of plant materials, the type of landscape at their residence and whether desert plants or desert landscapes were congruent with the architectural style of their residence. For the type oflandscape, homeowners were asked whether their landscape was a Southwest desert-type landscape, a traditional landscape or another type of landscape (Spinti, 2002). We defined a Southwest desert-type landscape as one that consisted mainly of desert plants adapted to the Southwest. In the survey instrument, we explained to participants that a traditional landscape consisted of nonnative turfgrass and nonnative plants (Spinti, 2002). We did not solicit typical demographic information such as the participant's age. Participants were asked to provide information such as time spent in the desert and length of time at their current address. We judged that information to be more germane to this study. The survey instrument consisted of five-point Likert-scaled items (Ary et al., 1996), multiple choice, dichotomous and open ended questions. Response categories and their corresponding values for the five-point Likert-scaled items were as follows: 1 = strongly agree, 2 = agree, $3=$ undecided-neutral, $4=$ disagree and $5=$ strongly disagree. For multiple choice questions, participants were asked to select one answer out of three options to represent their response to given question. Dichotomous questions solicited either a positive or negative response to a given question. A typical open-ended question was "How long have you lived in the Southwest?"

After initial development, a fourmember panel that provided expertise in statistics, survey development and landscape horticulture reviewed the survey tool for face and content validity. A preliminary survey was administered to a class of 22 Master Gardeners. Changes were made to the survey instrument based on the suggested revisions of the Master Gardeners.

Many residents of Las Cruces, N.M., are bilingual, and some residents consider Spanish their primary language. For that reason, a Spanish version of the survey was developed using the following procedures. The revised questionnaire was translated from English to Spanish by one translator and from Spanish back to English by a different translator. Then, a third translator reviewed the three versions (original English, Spanish, and translated English) of the survey and created a Spanish version that reconciled or clarified any syntactic differences.

Both English and Spanish versions of the survey instrument were assessed for reliability using a test-retest given to 30 participants whose first language was English (20) or Spanish (10) to verify that responses were consistent over 2 weeks. A standard was set beforehand that specified $80 \%$ of responses should not deviate by more than one response category between the test and the retest. Three survey items failed this standard and were revised or eliminated.

Population and sample. The Informational Technologies Department of the city of Las Cruces maintains a computerized database of all $(25,000)$ Las Cruces houses with managed landscapes. According to the Informational Technologies Department, $25 \%$ of the houses are within each of the following property value categories: $\$ 80,000$ or below; $\$ 81,000$ to $\$ 130,000 ; \$ 131,000$ to $\$ 175,000$; and $\$ 176,000$ or above. Because we hypothesized that one of the factors that could influence water use is property value, the sample was stratified by those property values. A stratified sample ensured that all segments of the population were represented in the sample. A population of 25,000 requires a random sample of 378 subjects to maintain a statistically valid population sample (Krejcie and Morgan, 1970). To meet that requirement, a randomly computer-selected sample of 400 properties was drawn from the database. We queried the database for residential homeowners only because homeowners with landscapes are more likely to have made landscape choices (Spinti, 2002). However, 22 addresses in the sample were removed, because owners were out-of-city or out-of-state (15) or the owners were the city of Las Cruces (3), a financial institution (2) a realty company (1) or a construction company (1). So, a sample of 378 homeowners was retained and an approximately equal number (92 to 96) of residences was in each of the four property value cat- 
egories. To ensure that only residential homeowners returned the survey, we asked whether the home was rented or owned as a backup.

On 25 Feb. 2002, survey materials (in English and Spanish) were mailed to the $\mathbf{3 7 8}$ homeowners. Survey materials included the survey instrument in booklet form, a cover letter explaining the purpose of the survey, an incentive entry form and a preaddressed stamped envelope for returning the completed survey and incentive entry form. The incentive form provided a chance for respondents to win one of ten $\$ 25$-dollar gift certificates to local businesses.

Survey booklets were color coded by property value category to ensure that returned surveys were quickly identified by property value. To guarantee that a completed survey could be traced to an individual respondent, each booklet was identified by a number unique to the potential respondents name. These procedures facilitated coding of the data for statistical analysis.

After 7 weeks (19 Apr. 2002), 154 completed surveys ( $41 \%$ response rate) were returned and a second survey was mailed to the 224 nonrespondents. Mailing procedures were similar to first mailing except that booklets were marked to separate the first from the second returned surveys. Data could then be analyzed statistically for differences between early (first returns) and late (second returns) responders. At the onset of the second mailing, the cut off date for accepting returned surveys was set at 7 June 2002 (7 weeks later). By that time, 44 more completed surveys were returned. Thus, 198 completed surveys (52\% response rate) were returned. Only one completed survey was returned after the cut off date and this survey was excluded from the study. Property values and the number of surveys (in parenthesis) which were returned for each property value group were: $\$ 80,000$ or below (35); $\$ 81,000$ to $\$ 130,000$ (54); $\$ 131,000$ to $\$ 175,000$ (61); and $\$ 176,000$ or above $(48)$. We also described the property value groups as low $(\$ 80,000$ or below), low-middle $(\$ 81,000$ to $\$ 130,000)$, middle-up$\operatorname{per}(\$ 131,000$ to $\$ 175,000)$ and high ( $\$ 176,000$ or above).

Data ANALYsis. Data were analyzed using the Statistical Analysis System (SAS) for Windows [Release 8.2 (SAS Inc., Cary, N. C.)]. Responses of early and late responders were compared using chi-square $\left(\chi^{2}\right)$ and t tests and were found to be statistically similar. Therefore, the two data sets were combined into a single sample for all subsequent statistical analysis. One participant reported that they rented their property. After a telephone conversation with this respondent, we gathered that respondent lived in adjoining quarters of a two-family residential unit and was the secondary owner of the property. The respondent had consulted with the primary owner and completed the survey on behalf of both families. We deemed that the participant had the characteristics of a homeowner and included the survey data in our final results. Intraclass correlation of items within a set was determined by using Cronbach's alpha scores. All alpha scores were $>0.70$ suggesting that there was sufficient internal consistency among items. Preliminary statistical analyses of the responses either compared or controlled for the effect of property value group. If the analysis revealed that property value was not statistically significant, then either the data or the estimates were pooled across property values. Homogeneity of property value group distributions was assessed using Monte Carlo estimates of Fisher's exact test $P$ values instead of $\chi^{2}$ approximation because several expected cell frequencies were too small for the $\chi^{2}$ approximations to be valid. Logistic regression was used to explore associations between a dichotomous response variable and other variables while controlling for property value groups. For those associations where neither property value main effects nor interactions involving property value groups were significant, data for the four groups were pooled and the simple association was reported. A hierarchical linear model analyzed selected sets of items of the survey and assessed differences between mean responses to items within a set. Least squares means (adjusted for property value) were used to rank items within a set. Least significant difference $(P \leq 0.05)$ was used to identify statistical differences among least squares means.

\section{Results and discussion}

Design features homeowners VALUE IN THEIR LANDSCAPES. Respondents indicated that the most important reasons to landscape their yard were to make their home and yard attractive and to increase the value of their property (Table 1). For the participants responding that the most important reason to landscape was to make my house attractive, there was a significant difference $(P=0.03)$ among property value groups. Fewer respondents (94\%) in the lowest property value group strongly agreed or agreed with that statement compared to $98 \%$ for low-middle, $100 \%$ for middle-high and $98 \%$ for the highest property value

Table 1. Responses (\%) of Las Cruces, N.M., respondents $(n=187)$ to each survey item when they were asked to give the most important reasons to landscape their yard. ${ }^{\mathrm{z}}$ Survey items are arranged in decreasing order of importance based on the least squares means.

\begin{tabular}{|c|c|c|c|c|c|c|}
\hline \multirow{3}{*}{$\begin{array}{l}\text { Survey } \\
\text { item }\end{array}$} & \multicolumn{5}{|c|}{ Response (\%) } & \multirow{3}{*}{$\begin{array}{c}\text { Least } \\
\text { squares } \\
\text { means }\end{array}$} \\
\hline & \multicolumn{5}{|c|}{ Response category ${ }^{y}$} & \\
\hline & SA & A & $\mathrm{U}$ & $\mathbf{D}$ & SD & \\
\hline To make my yard more attractive & 58.2 & 41.3 & 0.5 & 0 & 0 & $1.4 \mathrm{a}^{\mathrm{x}}$ \\
\hline To make my house more attractive & 58.3 & 39.7 & 1.6 & 0.5 & 0 & $1.5 \mathrm{a}$ \\
\hline To increase the property value & 40.6 & 49.2 & 7.5 & 2.2 & 0.5 & $1.8 \mathrm{~b}$ \\
\hline To provide a place to play or relax & 35.6 & 47.3 & 10.6 & 5.3 & 1.2 & $1.9 \mathrm{~b}$ \\
\hline To provide shade & 28.0 & 47.9 & 13.4 & 9.1 & 1.6 & $2.1 \mathrm{c}$ \\
\hline To express my landscape preferences & 9.8 & 40.8 & 30.4 & 15.2 & 3.8 & $2.6 \mathrm{~d}$ \\
\hline To create an area that contrasts with the desert & 6.5 & 18.4 & 39.5 & 25.4 & 10.3 & $3.1 \mathrm{e}$ \\
\hline
\end{tabular}

"Participants were asked to indicate their response level for each survey item after being presented with the statement, "The most important reasons for landscaping are". yStrongly agree (SA), agree (A), undecided/neutral (U), disagree (D), or strongly disagree (SD).

${ }^{x}$ Least squares means [based on a Likert scale of 1 to 5 (Ary et al., 1996)] with the same letter do not differ significantly (least significant difference, $P \leq 0.05$ ). 
Table 2. Responses (\%) of Las Cruces, N.M., homeowners $(n=187)$ when asked to give their feelings about using trees in their landscape. Survey items are arranged in decreasing order of importance based on the least squares means.

\begin{tabular}{|c|c|c|c|c|c|c|}
\hline \multirow{3}{*}{$\begin{array}{l}\text { Survey } \\
\text { item }\end{array}$} & \multicolumn{5}{|c|}{ Response (\%) } & \multirow{3}{*}{$\begin{array}{c}\text { Least } \\
\text { squares } \\
\text { means }\end{array}$} \\
\hline & \multicolumn{5}{|c|}{ Response category $^{\mathrm{y}}$} & \\
\hline & SA & A & $\mathrm{U}$ & $\mathbf{D}$ & SD & \\
\hline Trees make an area more beautiful & 47.9 & 46.8 & 2.1 & 3.2 & 0 & $1.6 \mathrm{a}$ \\
\hline Trees are part of the landscape I desire & 34.2 & 52.6 & 7.9 & 4.2 & 1.1 & $1.9 \mathrm{~b}$ \\
\hline Trees increase the value of a home & 29.8 & 43.1 & 20.7 & 5.9 & 0.5 & $2.1 \mathrm{c}$ \\
\hline
\end{tabular}

${ }^{2}$ Strongly agree (SA), agree (A), undecided/neutral (U), disagree (D), or strongly disagree (SD).

y Least squares means [based on a Likert scale of 1 to 5 (Ary et al., 1996)] with the same letter do not differ significantly (least significant difference, $P \leq 0.05$ ).

Table 3. Percentage of homeowners $(n=192)$ in Las Cruces, N.M., who indicated the actual type of landscape that they had in either their front yard or back yard.

\begin{tabular}{lcc}
\hline & \multicolumn{2}{c}{ Response (\%) } \\
\cline { 2 - 3 } Type of Landscape & Front yard & Back yard \\
\hline Southwestern U.S. desert-type landscape & 50.5 & 23.0 \\
Traditional landscape (turf and nonnative trees) & 45.4 & 69.4 \\
Other & 4.1 & 7.6 \\
\hline
\end{tabular}

group. Only half the respondents $(50.6 \%)$ strongly agreed or agreed that the main reason to landscape was to display their landscape preferences. These results suggest that homeowners valued individual landscape characteristics such as plant vigor (Abelló et al., 1986) and flower color (Lockett et al., 2002) over the landscape type.

Participants cited shade and aesthetics as the most important reasons for using trees in their landscape (Table 2 ). An increase in property value was only the fourth most important reason to plant trees in the landscape (Table 2 ). Taken together, these data suggest that in a desert environment, the function of trees rather than the perceived increase in property value might be the favored reason to include trees in a designed landscape. Although assign- ing a monetary value to tree cover is difficult (Anderson and Cordell, 1988), our results clearly suggest that the economic contribution of trees is not the predominant reason why trees are valued in a desert environment.

Desert plants as Vegetation in A LANDSCAPE. Many participants indicated they would use desert plants to landscape their front yard $(80.3 \%)$ and back yard (56.3\%). However, a relatively lower percentage of participants had actually created a front or back yard that uses desert landscaping (Table 3). Participants (56\%) indicated that they would like to change their current landscape but reported that financial constraints were barriers to making those changes. The fact that more participants in the lower $(60 \%)$ and lower-middle (52\%) income cat- egory than in the middle-high $(38 \%)$ and high $(30 \%)$ property value category reported that they would like to alter their landscape supported this observation.

In a desert environment, landscape designers and architects attempt to match the architectural style of a home, such as the Southwestern style with the type of landscape (Vanderbilt, 1998). When asked whether a desert landscape was appropriate for their home style, participants' responses differed $(P=$ 0.02 ) according to their respective income category. Seventy percent of participants in the lower income group felt desert plants matched the style of their home which was less than the 85\% (low-middle), 93\% (middle-high) and $81 \%$ (high) reported for the other property value groups.

A landscape preference study indicated that residents would use plants native to the semiarid Southwest if the plants were attractive (Lockett et al., 2002). Our research showed that among plant characteristics such as, attractiveness, functionality, price, and plant availability, participants ranked plant attractiveness as the most important reason to use desert plants in their

Table 4. Responses (\%) of Las Cruces, N.M., homeowners $(\mathrm{n}=187)$ when asked to give their feelings about using desert plants in landscapes. Survey items are arranged in decreasing order of importance based on the least squares means.

\begin{tabular}{|c|c|c|c|c|c|c|}
\hline \multirow{3}{*}{$\begin{array}{l}\text { Survey } \\
\text { item }\end{array}$} & \multicolumn{5}{|c|}{ Response (\%) } & \multirow{3}{*}{$\begin{array}{c}\text { Least } \\
\text { squares } \\
\text { means }\end{array}$} \\
\hline & \multicolumn{5}{|c|}{ Response category ${ }^{y}$} & \\
\hline & SA & A & $\mathrm{U}$ & $\mathrm{D}$ & SD & \\
\hline They provide the landscape I desire & 24.5 & 37.8 & 15.4 & 18.1 & 4.3 & $2.4 \mathrm{~b}$ \\
\hline They provide the variety I desire & 12.6 & 44.3 & 24.0 & 14.2 & 4.9 & $2.6 \mathrm{bc}$ \\
\hline They provide enough green & 10.8 & 42.2 & 17.3 & 24.9 & 4.9 & $2.7 \mathrm{c}$ \\
\hline They are too expensive & 2.7 & 14.1 & 37.3 & 33.5 & 12.4 & $3.3 \mathrm{e}$ \\
\hline They are unavailable or I can not find & 0 & 5.5 & 30.1 & 40.4 & 24.0 & $3.8 \mathrm{f}$ \\
\hline
\end{tabular}

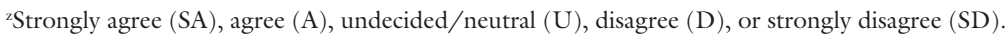

y Least squares means [based on a Likert scale of 1 to 5 (Ary et al., 1996)] with the same letter do not differ significantly (least significant difference, $P \leq 0.05$ ). 


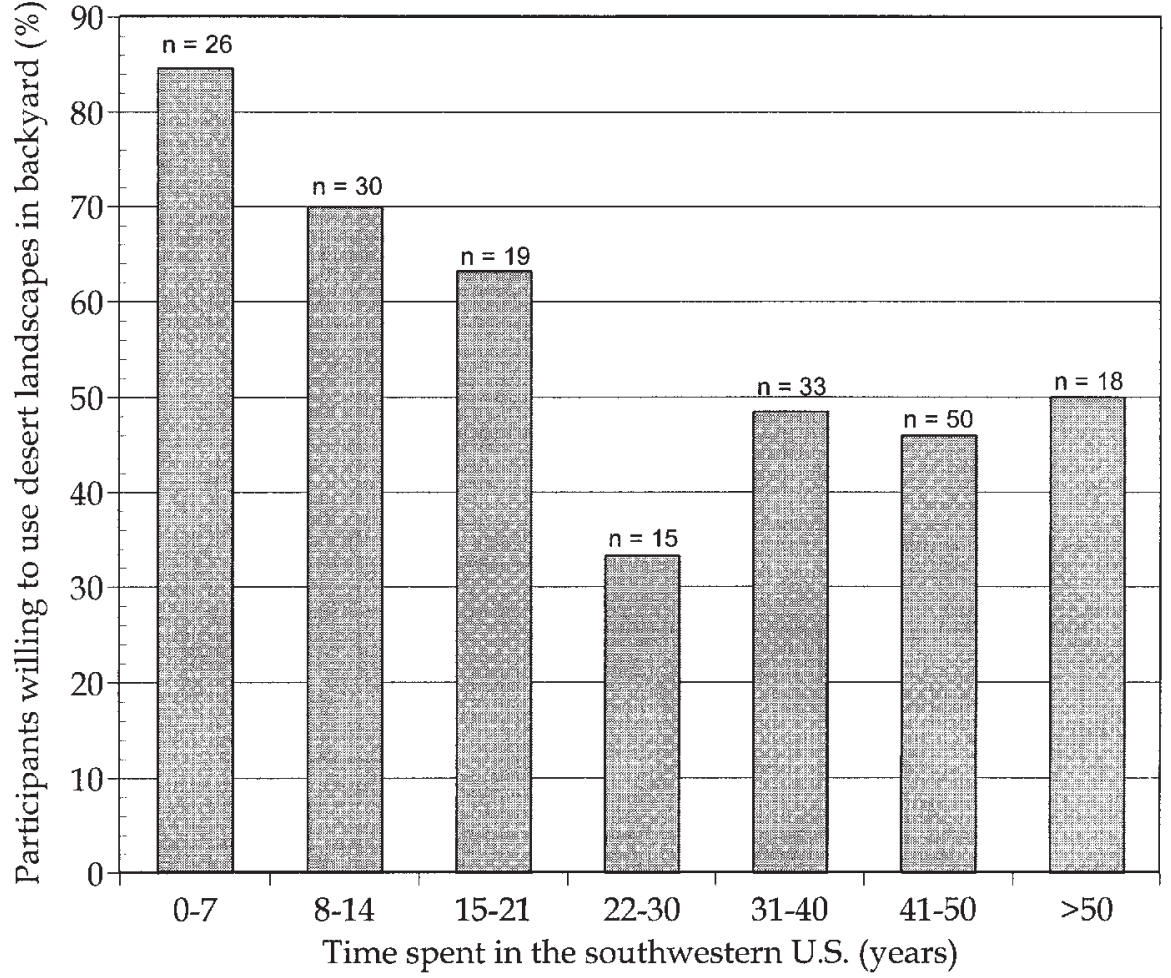

Fig. 1. Relationship between time spent in southwestern U.S. and the percentage of participants $(n=191)$ who reported willingness to use desert landscapes in their backyards. Logistical regression equation is logit $=-1.743-0.0945$ year + 0.0011 year $^{2}$.

landscapes (Table 4). While homeowners did not perceive that desert plants were unavailable, $57 \%$ of respondents indicated (strongly agree or agree) that desert plants provide the variety of plant materials that they desired. However, $39 \%$ of participants indicated that desert plants were not their favorite plants (Table 4). Thus, landscape architects and designers working in the Southwest should consider having an appropriate mix of nondesert and desert plants in their plant palette to meet the needs of their residential clients.

ReLATIONSHIP BETWEen RESIDENCY IN THE Southwest and Landscape PREFERENCE. Earlier studies have reported that as the length of residency in desert environments increased, there was an increased acceptance of desert landscaping because residents became more familiar with desert landscapes over time (Kennedy and Zube, 1991; Lyons, 1983). In contrast, the logistic regression of the willingness to use desert landscaping in the backyard on the length of time in the Southwest revealed a significant negative association regardless of property value groups. Furthermore, a quadratic function (linear coefficient $P=0.003$, quadratic coefficient $P=0.009$ ) could be used to model the relationship (Fig. 1). Thus, regardless of property value, homeowners were more likely to report willingness to use desert plants in their backyard the shorter their stay in the desert. There was no association between the years spent in the Southwest, or years spent in rural areas, with a willingness to use desert landscaping in the front yard. Familiarity with the desert and the willingness to use desert landscapes in the front yard might be different constructs. So, further studies to address this issue are warranted.

We found a significant property value $\times$ time spent in the desert interaction $(P=0.041)$ for the actual front yard landscape type homeowners had in their landscapes. With increasing time in the Southwest, a decreasing number of respondents in low-middle, middle-high and high property groups indicated they had desert landscapes in their yards. However, this trend was not observed for respondents in the low income group. One possible explanation is that respondents in the lower income group lived in the older, central part of the city and may have well-established traditional landscapes. Indeed, there was a significant association $(P=0.005)$ between property value and residency in the Southwest. Seventy-six percent of persons in the lowest property value group indicated they had always lived in the Southwest compared to $48 \%$ (low-middle), $39 \%$ (middle-high) and 44\% (high) for the other property value groups. Given that more respondents in the low-middle $(85 \%)$, middle-high $(93 \%)$ and high $(81 \%)$ property groups compared to the low property group (75\%) reported that desert plants matched the style of their home, it is likely that many relatively new homeowners of the city were in the higher income groups, lived on the fringes of the city and had more desert-type landscapes. Further studies are needed to provide more evidence for this.

Factors that inflUENCE REDUC-

Table 5. Responses (\%) of Las Cruces, N.M., homeowners $(\mathbf{n}=187)$ when asked to indicate which of the following survey item would cause them to use less water on their landscape. Survey items are arranged in decreasing order of importance based on the least squares means.

\begin{tabular}{|c|c|c|c|c|c|c|}
\hline \multirow{3}{*}{$\begin{array}{l}\text { Survey } \\
\text { item }\end{array}$} & \multicolumn{5}{|c|}{ Response (\%) } & \multirow{3}{*}{$\begin{array}{c}\text { Least } \\
\text { squares } \\
\text { means }\end{array}$} \\
\hline & \multicolumn{5}{|c|}{ Response category ${ }^{y}$} & \\
\hline & SA & A & $\mathrm{U}$ & $\mathbf{D}$ & SD & \\
\hline Water shortages & 39.5 & 53.0 & 6.0 & 0.5 & 1.1 & $1.7 \mathrm{a}^{\mathrm{y}}$ \\
\hline Environmental concerns & 22.6 & 48.9 & 21.0 & 6.5 & 1.1 & $2.2 \mathrm{~b}$ \\
\hline High water bills & 25.3 & 46.2 & 13.4 & 14.5 & 0.5 & $2.2 \mathrm{~b}$ \\
\hline Water rate increases & 24.6 & 47.1 & 13.9 & 13.4 & 1.1 & $2.2 \mathrm{~b}$ \\
\hline City regulations & 16.1 & 57.0 & 16.1 & 8.6 & 2.2 & $2.3 \mathrm{~b}$ \\
\hline Information on water conservation & 15.4 & 51.1 & 24.5 & 8.0 & 1.1 & $2.3 \mathrm{~b}$ \\
\hline
\end{tabular}

${ }^{\mathrm{z}}$ Strongly agree (SA), agree (A), undecided/neutral (U), disagree (D), or strongly disagree (SD).

'Least squares means [based on a Likert scale of 1 to 5 (Ary et al., 1996) with the same letter do not differ significantly (least significant difference, $P \leq 0.05$ ). 
TIONS IN LANDSCAPE WATER USE. OUI survey revealed homeowners in Las Cruces, N.M. considered that water shortages were the most important factor that would cause them to apply less water to their landscape (Table 5). Based on the value of the least squares means, homeowners of Las Cruces considered factors such as city regulations and water rate increases would have the same influence on reducing landscape water consumption (Table 5 ). These results indicate that participants in our survey might be generally aware of the transient nature of their future water supply. Indeed, Brown et al. (2000), found that $57 \%$ of the respondents in Rio Rancho, N.M. responded that the amount of water available to them would be a critical issue in 35 years. In this study, we surveyed the literature for factors that have been reported to influence the amount of water residents apply to their landscapes. We then asked the participants in our survey to rank those items. Previous studies (Martin and Kulakowski, 1991; McPherson and Haip, 1989) have indicated that water shortages were less effective than water rate increases in reducing water use. However, based on our data, we conclude that homeowners of Las Cruces would most likely use less water in their landscape if they perceived a water shortage.

In summary, participants were most willing to landscape their yard because they felt that the aesthetics of their home and yard will be enhanced and the value of their property will be increased. However, specific landscape elements, such as trees were valued more for their function in the landscape than for their perceived impact on property values. Although a large percentage of respondents would use desert plants to landscape their property, financial constraints could be a reason why a lower percentage of participants reported they had created a landscape that used desert landscaping. Regardless of property value, participants were more amenable to using desert plants in their backyard the shorter their residency in the Southwest. The type of landscape homeowners had in their front yard was associated with the value of their property. Our data revealed that water shortages were the most likely reasons that would cause homeowners in this desert environment to reduce the amount of water applied to landscapes.

\section{Literature cited}

Abelló, R.P., F.G. Bernáldez, and E.F. Galiano. 1986. Consensus and contrast components in landscape preferences. Environ. Behavior 18:155-178.

Anderson, L.M. and H.K. Cordell. 1988. Influence of trees on residential property values in Athens, Georgia (U.S.A): A survey based on actual sales prices. Landscape Urban Planning 15:153-164.

Ary, D., L.C. Jacobs, and A. Razavieh. 1996. Introduction to research in education. $5^{\text {th }}$ ed. Harcourt Brace College Publ., Orlando, Fla.

Barton, S.S, J.R. Brooker, C.R. Hall, and S.C. Turner. 1998. Review of customer preference research in the nursery and landscape industry. J. Environ. Hort. 16: 118-124.

Brown, J.R., N. Carrillo, and H. JenkinsSmith. 2000. Attitudes and preferences of residents of the middle Rio Grande water planning region regarding water issues. Univ. of N.M. Inst. Public Policy, Albuquerque.

Cotter, D.J. and D.B. Croft. 1974. Water application practices and landscape attributes associated with residential water consumption. N.M. State Univ. Proj. Completion Rpt. No. C-4060-NMEX, N.M. Water Resour. Res. Inst., Las Cruces.

Earp, D., J. Postlethwait, and J. Witherspoon. 2000. Albuquerque's environmental story. Environmental topic: Water. 3 Oct. 2000. <http://www.cabq.gov/aes/ s5water.html.>.

Emrath, P. 2000. Residential water use. Housing Econ. 48:6-10.

Ferguson, B.K. 1987. Water conservation methods in urban landscape irrigation: An exploratory overview. Water Resourc. Bul. 23:147-152.
Herzog, T.R. and G.J. Barnes. 1999. Tranquility and preference revisited. J. Environ. Psychol. 19:171-181.

Kennedy, C.B. and E.H. Zube. 1991. Attitudes towards vegetation in a desert urban forest: Creating a sense of place. J. Arboricult. 17:159-166.

Krejcie, R.V. and D.W. Morgan. 1970. Determining sample size for research activities. Educ. Psychol. Measurement 30:607-610

Kuo, F.E., M. Bacaicoa, and W.C. Sullivan. 1998. Transforming inner-city landscapes: Trees, sense of safety, and preference. Environ. Behavior 30:28-59.

Lockett, L., T. Montague, C. McKenney, and D. Auld. 2002. Assessing public opinion on water conservation in the semiarid southwestern United States. Hort Technology 12:392-396.

Lohr, V.I. and L.H. Bummer. 1992. Assessing and influencing attitudes toward water-conserving landscapes. HortTechnology 2:253-256.

Lyons, E. 1983. Demographic correlates of landscape preference. Environ. Behavior 15: 487-511.

Martin, W.E. and S. Kulakowski. 1991. Water price as a policy variable in managing urban water use: Tucson, Arizona. Water Resources Res. 27:157-166.

McPherson, E.G. and R.A. Haip. 1989. Emerging desert landscape in Tucson. The Geographical Review 79:435-449.

Paine, T.D., C.C. Hanlon, D.R. Pitenger, D.M. Ferrin, and M.K. Malinoski. 1992. Consequences of water and nitrogen management on growth and aesthetic quality of drought-tolerant woody landscape plants. J. Environ. Hort. 10:94-99.

Spinti, J.E. 2002. Balancing landscape preferences and water use in a desert environment. MS thesis. N.M. State Univ., Las Cruces.

Thayer, R.L. 1982. Public response to water conserving landscapes. HortScience 17: $562-565$

Vanderbilt, T. 1998. Desert refuge. Landscape Architecture 88:18, 20, 22-23.

Zube, E.H., D.E. Simcox, and C.S. Law. 1986. The oasis image in two desert cities. Landscape Res. 11:7-11. 